\title{
CFD Analysis of the Influence of Meteorological Conditions on Motion of Ammonia
}

\author{
Ondřej Zavila ${ }^{1 *}$, Marian Bojko², Milada Kozubková2, Pavel Danihelka ${ }^{3}$, Barbora \\ Baudišová ${ }^{3}$, Lenka Maléřová ${ }^{2}$ and Mária Čarnogurská ${ }^{5}$ \\ 'Department of Fire Protection, VSB - Technical University of Ostrava, Lumírova 13/630, Ostrava - Výškovice,70030, Czech Republic \\ ${ }^{2}$ Department of Hydrodynamics and Hydraulic Equipment, VSB - Technical University of Ostrava, 17. listopadu 15/2172, Ostrava - Poruba, \\ 70800, Czech Republic \\ ${ }^{3}$ Energy Research Center Innovation for Efficiency and Environment, VSB - Technical University of Ostrava, 17. listopadu 15/2172, Ostrava - \\ Poruba, 708 00, Czech Republic \\ ${ }^{4}$ Department of Civil Protection, VSB - Technical University of Ostrava, Lumírova 13/630, Ostrava - Výškovice, 700 30, Czech Republic \\ ${ }^{5}$ Department of Power Engineering, Technical University of Košice, Faculty of Mechanical Engineering, Vysokoškolská 4, 04200 Košice
}

\section{BIOGRAPHICAL NOTES}

Ondřej Zavila, Ing., Ph.D., (1980). I am a lecturer at VSB - Technical university of Ostrava, Faculty of Safety Engineering. I graduated from the Faculty of Safety Engineering (VSB - Technical university of Ostrava) in 2004 (academic title "Ing." in the field of "Fire protection and civil protection") and 2007 (academic title "Ph.D." in the field of "CFD numerical modeling"). My professional and research specialization is the branch of CFD numerical modeling (fluid mechanics), fire protection and survival. In the field of CFD numerical modeling I have focused on problem of turbulent flow and pollutant motion and dispersion in the atmospheric boundary layer. Among all my significant publications there are 5 scientific articles on Scopus database, 2 scientific articles on Web of Knowledge database, 3 international scientific book chapters, etc.

Marian Bojko, Ing., Ph.D., (1979). I am a lecturer at VSB - Technical university of Ostrava, Faculty of Mechanical Engineering. I graduated from the Faculty of Mechanical Engineering (VSB - Technical university of Ostrava) in 2002 (academic title "Ing." in the field of "Hydraulic and mechanical machines and equipment") and 2006 (academic title "Ph.D." in the field of "Hydraulic and mechanical machines and equipment"). My professional and research specialization is the branch of CFD numerical modeling and fluid mechanics. In the field of CFD numerical modeling I have focused on problem of turbulent flow and heat transfer. Among all my significant publications there are 12 scientific articles on Scopus database, 4 scientific articles on Web of Knowledge database, 2 international scientific book chapters, etc.

Milada Kozubková, prof., RNDr., CSc., (1952). I am a full professor at VSB - Technical university of Ostrava, Faculty of Mechanical Engineering. I graduated from the Faculty of Science (Palacky University Olomouc) in 1980 (academic title "RNDr." in the field of "Mathematical analysis") and in 1990 (academic title "CSc." in the field of "Construction of energetic machines and equipment"). In next I graduated from the Faculty of Mechanical Engineering (VSB - Technical university of Ostrava) in 2000 (academic title "Associated Professor" in the field of "Applied mechanics") and in 2010 (academic title "Full Professor" in the field of "Applied mechanics"). My research activities and specialization are focused on fluid mechanics and numerical mathematics. Among all my significant publications there are 12 scientific articles on Scopus database, 10 scientific articles on Web of Knowledge database and many other research publications.

Pavel Danihelka, prof., RNDr., CSc., (1953), graduated 1977 at Faculty of Natural Sci- 
ences, Charles University Prague, Czech Republic, contemporary head of the Laboratory of Risk Research and Management and senior researcher at Energy Research Centre. In various periods I was a member of scientific boards of 4 faculties in Czech and Slovakia, member of Committee Scientific d'Evaluation des Ecoles des Mines (France), National expert in the Horizon 2020 Program Committee "Secure Societies", member of Joint Expert Group on Trans-boundary Accident of UNECE, NATO Environment Security Panel, Committee of Competent Authorities of Seveso II Directive and OECD Working Group on Chemical Accidents. Nowadays I am President of the Czech Technological Platform on Industrial Safety oriented to the safety and security related to dangerous chemicals, environmental security and nanotechnology safety. I am the author or co-author of more than a hundred scientific publications, 4 patents, 6 national and 2 international certified methodics in major accident prevention.

Barbora Baudišová, Ing. , (1983). I am a scientist researcher at VSB - Technical university of Ostrava. I graduated from the Faculty of Safety Engineering (VSB - Technical university of Ostrava) in 2007 (academic title "Ing.") and currently studying for Ph.D. My professional and research specialization is major accident hazard, civil protection, risk analysis and acute toxicity. Among all my significant publications there are 1 proceedings paper on Scopus database, 2 proceedings paper on Web of Knowledge database, etc.

Lenka Maléřová, Ing., (1983). I am lecture and external Ph.D. student at the Department of Civil Protection of the Faculty of Safety Engineering, VSBTechnical university of Ostrava. I graduated from the Faculty of Safety Engineering in 2006 with academic title "Ing" in the field of "Fire protection and civil protection". My professional and study field is focused on the issues of people protection with priority to search for methods of risk analysis in the consideration and determination of measures to mitigate their impact. My significant publications are 3 scientific articles on Scopus database, etc.

Mária Čarnogurská, prof., Ing., CSc., (1953). is a graduate of Faculty of Mechanical Engineering, Technical University in Kosice (1977). Currently works as a Head of Department of Power Engineering at Faculty of Mechanical Engineering at a. $m$. university. Her long-term professional focus is the area of power engineering. Her research is concentrating on mathematical and physical modeling of processes and effects applied in power engineering, the flow of various media in energy machines and equipment as well as the exploitation of unused heat energy in diverse industrial applications. She is the author of 4 monographs. From all of her significant publications there are 9 scientific articles published in Web of Knowledge database, 2 scientific articles published in Scopus database and many other research publications.

\section{KEY WORDS}

CFD; model; gas; Pollutant; Gravitational forces; Ice stadium.

\section{ABSTRACT}

The article presents the results of a numerical CFD model of gas ammonia plume motion and dispersion after an accidental release from a real ice stadium situated in an urban area. The CFD analysis was performed using the ANSYS Fluent 14.0 for two seasons and eight wind directions. Sixteen tasks emerged, the results of which can define the influence of meteorological conditions (wind direction, wind speed, temperature, etc.) and surrounding buildings on the motion and dispersion of pollutant plume. The simulation was performed with real local meteorological data. The numerical model had been verified by tasks performed in a low-speed wind tunnel. The results show that the influence of meteorological conditions, especially the influence of calendar seasons, on the pollutant plume propagation can be very pronounced. Principles and conclusions drawn from this and similar analyses may have great benefits for emergency planning in complex urban areas.

\section{INTRODUCTION}

Ammonia in all physical states is a toxic substance that can endanger people's health. It is used in various industrial technologies, including freezing of ice surfaces in ice stadiums. There exist advanced ammonia-free technologies but in many places liquid ammonia is still used in large volumes. It is no exception that objects using ammonia cooling and freezing technologies are placed in densely populated urban areas or in their immediate vicinities. An accidental ammonia release can pose a risk to health and lives of humans located in 
the release source immediate vicinity.

\section{Ammonia accidental release scenarios}

A real ice stadium (see Figure 1) located in the middle of an urban development (residential and industrial zones) in the Czech Republic was subject to simulation. The ice stadium main building has an octagonal ground plan with dimensions $110 \mathrm{~m}$ $\times 115 \mathrm{~m}$ and a total clear height $31 \mathrm{~m}$. The ice surface freezing is carried out with a technology that uses liquid ammonia. Most of the system technological components, including the ammonia storage, are placed in the machinery room from where the system is controlled too. The machinery room is equipped with an emergency ventilation system for cases of damage to the storage tank or other technology elements. The system consists of ammonia sensors, a control panel and several vacuum fans that extract air from the machinery room and blow it outside the stadium into the atmosphere through vent holes. Only $50 \mathrm{~m}$ away a residential building can be found.

In the accidental release scenario, damage to a freezing system element is assumed with liquid ammonia spill in the machinery room. Due to the ambient temperature, the liquid ammonia starts to evaporate and in the gas state it is discharged by the emergency ventilation system to the exterior where it disperses.

The ammonia plume dispersion was modeled for eight cardinal and ordinal wind directions (north, northeast, east, southeast, south, southwest, west, and northwest) and two seasons (summer and winter). Wind velocities and frequencies of occurrence for different wind directions as well as the ambient air temperature and the pollutant source temperature differ for the two seasons. All meteorological input data were obtained from the Czech Hydrometeorological Institute (CHMI) [1] database and they represent mean values of meteorological variables measured over the period 2006-2011. The parameters for accidental release of ammonia were based on a qualified estimate of the technology administrator and on the ice stadium internal technical documentation.

\section{CFD numerical model - ANSYS Fluent software}

CFD (Computational Fluid Dynamics) codes are represented by ANSYS Fluent version 14.0. It is a sophisticated commercial software tool for fluid me-

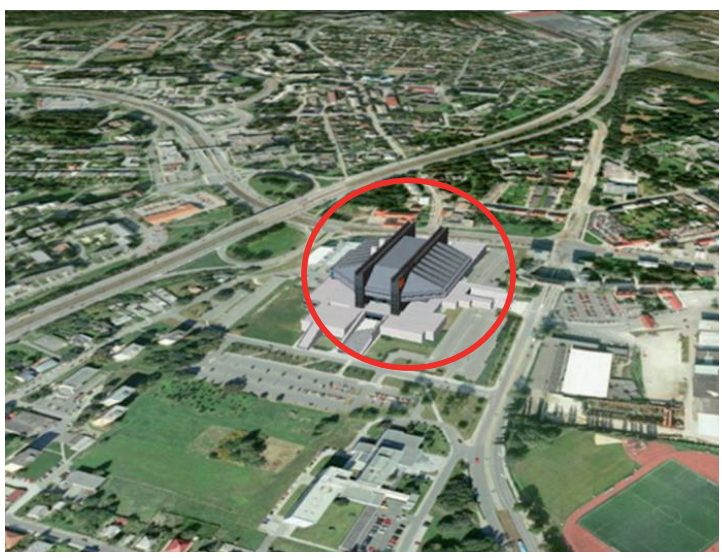

Fig. 1: Photo of a real ice stadium and its close surrounding in Central European region.

chanics and heat transfer computations. It offers a wide range of sub-models, corresponding input data sets and options. Models included in the software are based on numerical solution of systems of partial differential equations that express the law of conservation of mass (continuity equation), the law of conservation of momentum (Navier-Stokes equations) and the law of conservation of energy (energy equation). This basic set of equations can be supplemented by additional equations that express heat transfer (heat transfer equations - convection, conduction or radiation), or species transport (species transport equations - gas, liquid or solid). The system of equations is then solved with an appropriate numerical method; in this case, with the finite-volume method. The model computes in both 2D and 3D geometries. Calculation results can be visualized as filled or unfilled contours of physical fields, iso-surfaces, animations, 2D value diagrams or numerical data sets.

The continuity equation, Navier-Stokes equations and energy equations are used to calculate the air turbulent flow field. The species transport equation applies to gas pollutant release $[2,3]$.

\subsection{Continuity equation for compressible fluid flow}

The continuity equation expresses the law of conservation of mass. For unsteady (time-dependent) compressible fluid flows, it can be written in differential form as

$$
\frac{\partial \rho}{\partial t}+\frac{\partial\left(\rho \cdot \bar{u}_{j}\right)}{\partial x_{j}}=0
$$

where: $\rho$ is the fluid density kg.m ${ }^{-3}, t$ is time $\mathrm{s}, \bar{u}_{j}$ is the time-averaged $j$-coordinate of the fluid flow 
velocity $\mathrm{m} \cdot \mathrm{s}^{-1}$, and $x_{j}$ is a coordinate of the Cartesian coordinate system.

\subsection{Navier-Stokes equations for compressible fluid flow}

Navier-Stokes equations express the law of conservation of momentum. The substitution of the time-averaged values into the Navier-Stokes equations gives the Reynolds equations. The equation of transfer of momentum for compressible fluids can be written in the form corresponding to differential form as

$$
\frac{\partial\left(\rho \cdot \bar{u}_{i}\right)}{\partial t}+\frac{\partial\left(\rho \cdot \bar{u}_{i} \cdot \bar{u}_{j}\right)}{\partial x_{j}}=-\frac{\partial \bar{p}}{\partial x_{i}}+\frac{\partial}{\partial x_{j}}\left(\mu_{t} \cdot \frac{\partial \bar{u}_{i}}{\partial x_{j}}\right)+\rho \cdot \delta_{i 3} \cdot g+\rho \cdot f_{c} \cdot \varepsilon_{i j 3} \cdot \bar{u}_{j}+\rho \cdot f_{j}
$$

where: $\rho$ is the fluid density $\mathrm{kg} \cdot \mathrm{m}^{-3}, t$ is time $s, \bar{u}_{j}$ is the time-averaged $j$-coordinate of the fluid flow velocity $\mathrm{m} . \mathrm{s}^{-1}, x_{j}$ is a coordinate of the Cartesian coordinates system, $\bar{p}$ is the time-averaged value of pressure $\mathrm{Pa}, \mu_{t}$ is the turbulent dynamic viscosity Pa.s, $\delta_{i 3}$ is the Kronecker delta, $\varepsilon_{i j 3}$ is the unit tensor for centrifugal forces, $f_{j}$ is the $j$ - coordinate of force
$\mathrm{N}$, and $g$ is the gravity acceleration $\mathrm{m} \cdot \mathrm{s}^{-2}$ if buoyancy forces are present.

The equations to express the turbulent flow field variables are turbulent kinetic energy equation $k$ and dissipation rate equation $\varepsilon$. The exact equation for $k$ can be deduced from the Navier-Stokes equations and written as

$$
\frac{\partial k}{\partial t}+\frac{\partial \bar{u}_{j} \cdot k}{\partial x_{j}}=-\frac{\partial}{\partial x_{j}}\left[\overline{u_{j}^{\prime}} \cdot\left(\frac{u_{l}^{\prime} \cdot u_{l}^{\prime}}{2}+\delta_{j l} \cdot \frac{p^{\prime}}{\rho}\right)\right]+\nu_{t} \cdot \frac{\partial^{2} k}{\partial x_{j}^{2}}-\overline{u_{l}^{\prime} \cdot u_{j}^{\prime}} \cdot \frac{\partial \bar{u}_{l}}{\partial x_{j}}-\nu \cdot \overline{\frac{\partial u_{l}^{\prime}}{\partial x_{j}} \cdot \frac{\partial u_{l}^{\prime}}{\partial x_{j}}}
$$

where: $k$ is the turbulent kinetic energy $\mathrm{m}^{2} \cdot \mathrm{s}^{-2}, t$ is time $s, \bar{u}_{j}$ is time-averaged $j$-coordinate of the flu-

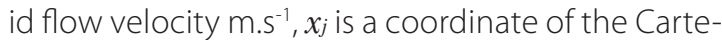
sian coordinate system, $\rho$ is the fluid density $\mathrm{kg} \cdot \mathrm{m}^{-3}$, $p^{\prime}$ is a component of pressure fluctuation $\mathrm{Pa}$ and $v_{t}$ is the turbulent kinematic viscosity $\mathrm{m}^{2} \cdot \mathrm{s}^{-1}$.

The turbulent kinetic energy $k$ in Eq. (3) is where: $\bar{u}_{j}$ represents time-averaged flow velocity components $\mathrm{m} \cdot \mathrm{s}^{-1}$. The exact equation for $\varepsilon$ can be deduced from the Navier-Stokes equations and written as

$k=\frac{1}{2} \cdot\left(\overline{u_{1}^{\prime 2}}+\overline{u_{2}^{\prime 2}}+\overline{u_{3}^{\prime 2}}\right)=\frac{1}{2} \cdot \overline{u_{j}^{\prime 2}}$

$\frac{\partial \varepsilon}{\partial t}+\frac{\partial \bar{u}_{j} \cdot \varepsilon}{\partial x_{j}}=\frac{\partial}{\partial x_{j}} \cdot\left(\frac{\nu_{t}}{\sigma_{\varepsilon}} \cdot \frac{\partial \varepsilon}{\partial x_{j}}\right)+C_{1 \varepsilon} \cdot \nu_{t} \cdot\left(\frac{\partial \bar{u}_{j}}{\partial x_{l}}+\frac{\partial \bar{u}_{l}}{\partial x_{j}}\right) \cdot \frac{\partial \bar{u}_{l}}{\partial x_{j}}-C_{2 \varepsilon} \cdot \frac{\varepsilon^{2}}{k}$

where: $\varepsilon$ is the turbulent dissipation rate $\mathrm{m}^{2} \cdot \mathrm{s}^{-3}, t$ is time $s, \bar{u}_{j}$ is the time-averaged $j$ - coordinate of the fluid flow velocity $\mathrm{m} . \mathrm{s}^{-1}, x_{j}$ is a coordinate of the Cartesian coordinate system, $v_{t}$ is the turbulent kinematic viscosity $\mathrm{m}^{2} . \mathrm{s}^{-1}, \sigma_{\varepsilon}, C_{1 \varepsilon}$ and $C_{2 \varepsilon}$ are empirical constants, and $k$ is the turbulent kinetic energy $\mathrm{m}^{2} \cdot \mathrm{s}^{-2}$. The turbulent kinematic viscosity $v_{t}$ is

$\nu_{t}=C_{\nu} \cdot \frac{k^{2}}{\varepsilon}$ where: $C_{v}$ is an empirical constant.

\subsection{Energy equation}

The energy equation expresses the law of conservation of energy. According to this law, the change in total energy of the fluid $\bar{E} \mathrm{~J} . \mathrm{kg}^{-1}$ in volume $V \mathrm{~m}^{3}$ is determined by the change in the internal energy, kinetic energy, and the flux of both energies through surface $S \mathrm{~m}^{2}$ that surrounds volume $V$. The final equation can be written as

$\frac{\partial}{\partial t}[\rho \cdot \bar{E}]+\frac{\partial}{\partial x_{j}}\left[\rho \cdot \bar{u}_{j} \cdot \bar{E}\right]=\rho \cdot \bar{u}_{j} \cdot f_{j}-\frac{\partial\left(p \cdot \bar{u}_{j}\right)}{\partial x_{j}}+\frac{\partial\left(\tau_{j l} \cdot \bar{u}_{j}\right)}{\partial x_{l}}-\frac{\partial \bar{q}_{j}}{\partial x_{j}}$

where: $t$ is time s, $\rho$ is the fluid density $\mathrm{kg} \cdot \mathrm{m}^{-3}, \bar{E}$ is the time-averaged value of energy J.kg-1, $\bar{u}_{j}$ is the time-averaged $j$-coordinate of the flow field velocity $\mathrm{m}^{-\mathrm{s}^{-1}}, x_{j}$ is a coordinate of the Cartesian coordinate system, $p$ is the pressure $\mathrm{Pa}, \tau_{j, l}$ is the tensor of viscous stress $\mathrm{Pa}$ and $\bar{q}_{j}$ is the time-averaged $j$ - coordinate of the heat flux J. $\mathrm{m}^{-2} \cdot \mathrm{s}^{-1}$.

\subsection{Gas pollutant release equation}

In the model, time-averaged values of the local species mass fraction $\bar{Y}_{i^{\prime}}$ are calculated. These values are described by a balance equation similar to the energy equation Eq. (7) that includes both convective and diffuse components of the transport. It can be written in conservative form as 


$$
\frac{\partial}{\partial t}\left(\rho \cdot \bar{Y}_{i^{\prime}}\right)+\frac{\partial}{\partial x_{j}} \cdot\left(\rho \cdot \bar{u}_{j} \cdot \bar{Y}_{i^{\prime}}\right)=-\frac{\partial}{\partial x_{i}} \cdot J_{j, i^{\prime}}+R_{i^{\prime}}+S_{i^{\prime}}
$$

where: $\bar{u}_{j}$ is the time-averaged $j$ - coordinate of the flow field velocity $\mathrm{m} . \mathrm{s}^{-1}, R_{i^{\prime}}$ is the production rate of species $i^{\prime}$ due to chemical reaction $\mathrm{kg} \cdot \mathrm{m}^{-3} \cdot \mathrm{s}^{-1}$ and $S_{i}$ is the increment production rate from distributed species $\mathrm{kg} \cdot \mathrm{m}^{-3} \cdot \mathrm{s}^{-1}$. The equation is valid for $N-1$ species, where $N$ is the total number of components included in the mathematical model. Species distribution can occur under various conditions. Generally, distribution under laminar and turbulent flow can be distinguished. $J_{j, i^{\prime}}$ represents the diffuse flux of the $i^{\prime}$-component of the mixture $\mathrm{kg} \cdot \mathrm{m}^{-2} \cdot \mathrm{s}^{-1}$. The diffuse flux of the $i^{\prime}$ component in the turbulent flow regime is

$$
J_{i^{\prime}}=-\left(\frac{\mu_{t}}{S c_{t}}\right) \cdot \frac{\partial \bar{Y}_{i^{\prime}}}{\partial x_{j}}
$$

where: $\bar{Y}_{i}$ is the time-averaged species $i^{\prime}$ product mass fraction and $S c_{t}$ is the Schmidt turbulent number (preset at the default value of 0.7).

\section{CFD model inputs}

Three software programs were used to accomplish the task: DesignModeler, ANSYS Meshing, and ANSYS Fluent $14.0[2,3]$. The geometry shape was created in DesignModeler. The grid system to cover the geometry was created in ANSYS Meshing. Numerical calculations of all task variants were carried out in ANSYS Fluent 14.0.

The cuboid-shaped geometry with dimensions of $800 \mathrm{~m}$ (width) $\times 800 \mathrm{~m}$ (length) $\times 150 \mathrm{~m}$ (height) represented a three-dimensional virtual model of the urban area terrain in the ice stadium vicinity (see Figure 2). The source data for creating the terrain model were obtained from the Czech Republic Cadaster Office map database. The geometry boundaries were oriented to the cardinal points (north, south, east, and west). The numerical model was made at a 1:1 scale. The geometry consisted of a grid of a total of approximately 1.6 million cells.

The task solving was split into two phases. In the first phase, stationary (time-independent) calculation of the turbulent flow field for air without species was performed. In the second phase, nonstationary (time-dependent) calculation of the species flow in that previously segmented turbulent air flow field. The air flow field was modeled

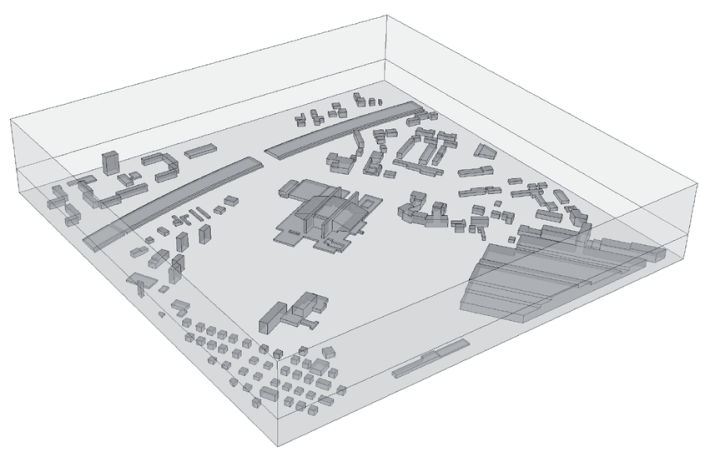

Fig. 2: Geometry of a real ice stadium and its close surrounding in Central European region.

with RNG k- $\varepsilon$ model of turbulence. The gas species motion and dispersion was modeled with Species model. Both models are included in ANSYS Fluent 14.0. The entire numerical problem was solved by finite volume numerical method.

The boundary conditions for the entire geometry were given by atmospheric pressure (101325 [Pa]), vertical profiles of air flow velocity (see Eq. (10)), turbulent kinetic energy (see Eq. (11)), turbulent dissipation velocity (see Eq. (12)), and temperature (see Eq. (13)). The geometry boundaries were defined by Wall type (the earth's surface and walls of buildings) and Mass Flow Inlet type (all four side walls) boundary conditions. The upper limit of the geometry was again defined as Wall, but with zero shear stress.

The air flow velocity vertical profile in the geometry was defined as $[2,3,4]$

$v=v_{\text {ref }} \cdot\left(\frac{z}{10}\right)^{p}$

where: $v$ is the air flow velocity $\mathrm{m} \cdot \mathrm{s}^{-1}$ in height $z \mathrm{~m}$ above the ground, vref is the referential air flow velocity $\mathrm{m} . \mathrm{s}^{-1}$ in height $z_{\text {ref }}=10 \mathrm{~m}$ above the ground and $p$ is the exponent for given atmospheric state (atmospheric stability class D according to PasquilGiffort scale) with the value of 0.14 .

The turbulent kinetic energy vertical profile in the geometry was defined as $[2,3,4]$

$k=\frac{v_{*}^{2}}{0.3}$ 
where: $k$ is the turbulent kinetic energy $\mathrm{m}^{2} \cdot \mathrm{s}^{-2}$ and $v^{*}$ is the shear velocity $\mathrm{m} \cdot \mathrm{s}^{-1}$ defined by the value of $0.4 \mathrm{~m} . \mathrm{s}^{-1}$ [4]. The shear velocity $v^{*}$ takes values depending on the air flow velocity and the atmospheric stability class according to Pasquil-Giffort scale.

The turbulent dissipation velocity vertical profile in the geometry was defined as $[2,3,4]$

$\varepsilon=\frac{\nu_{*}^{3}}{0.4 \cdot z}$

where: $\varepsilon$ is the turbulent dissipation velocity $\mathrm{m}^{2} \cdot \mathrm{s}^{-3}$, $v^{*}$ is the shear velocity $\mathrm{m} \cdot \mathrm{s}^{-1}$ and $z$ is the height $\mathrm{m}$ above the ground.

The air temperature vertical profile in the geometry was defined as $[2,3,4]$

$$
T=T_{0}+273.15+\gamma \cdot z
$$

where: $T$ is the air temperature $K$ in height $z \mathrm{~m}$ above the ground, $T_{0}$ is the average air temperature $K$ according to $\mathrm{CHMl}$ for given season and location, and $\gamma$ is the dry adiabatic lapse rate $\mathrm{K}_{\mathrm{m}} \mathrm{m}^{-1}$ defined by the value of $-0.0065 \mathrm{~K} . \mathrm{m}^{-1}$ for the atmosphere normal state.

The pollutant source (a vent hole for gas ammonia removal) was defined as an area source of dimensions $1.4 \mathrm{~m} \times 2.4 \mathrm{~m}$ located at a height of $6 \mathrm{~m}$ above the surrounding terrain with flow rate set to a constant value.

The referential velocity vref was defined within the range 1.1-1.6 m.s. for summer, with the greatest frequency of occurrence corresponding to southwest (frequency 23.1\%) and west (frequency 18.4\%) winds according to the CHMI wind rose [1]. The average air temperature $T_{0}$ was defined with a value of $291.95 \mathrm{~K}\left(18.8^{\circ} \mathrm{C}\right)$. The pollutant source temperature was set to $266.05 \mathrm{~K}\left(-7.1^{\circ} \mathrm{C}\right)$. The pollutant was defined as a mixture of gas ammonia and air where the mass fraction of $\mathrm{NH} 3$ was 0.37 .

The referential velocity vref was defined within the range 1.4-2.2 $\mathrm{m} . \mathrm{s}^{-1}$ for winter, with the greatest frequency of occurrence corresponding to southwest (frequency 35.7\%) and north (frequency 16.3\%) winds according to the CHMI wind rose [1]. The average air temperature $T_{0}$ was defined with a value of $273.05 \mathrm{~K}\left(-0.1^{\circ} \mathrm{C}\right)$. The pollutant source temperature was set to $256.6 \mathrm{~K}\left(-16.55^{\circ} \mathrm{C}\right)$. The pollutant was defined as a mixture of gas ammonia and air where the mass fraction of $\mathrm{NH} 3$ was defined with a value of 0.37 .

Calculation results were evaluated using cross sections of the 3D geometry located $1.5 \mathrm{~m}$ above the ground (human breathing zone) and gas ammonia concentration iso-surfaces representing zones with concentrations of $25 \mathrm{ppm}$ (threshold value for acute toxicity limit ERPG-1) and 150 ppm (threshold value for acute toxicity limit ERPG-2). Air flow velocity fields, turbulence intensities, temperatures and $\mathrm{NH}_{3}$ concentrations were evaluated in the geometry cross sections. All evaluations were performed for time points of $1 \mathrm{~min}, 3 \mathrm{~min}$, and 5 min from the onset of the pollutant escape from the ice stadium building (see Figure 3).
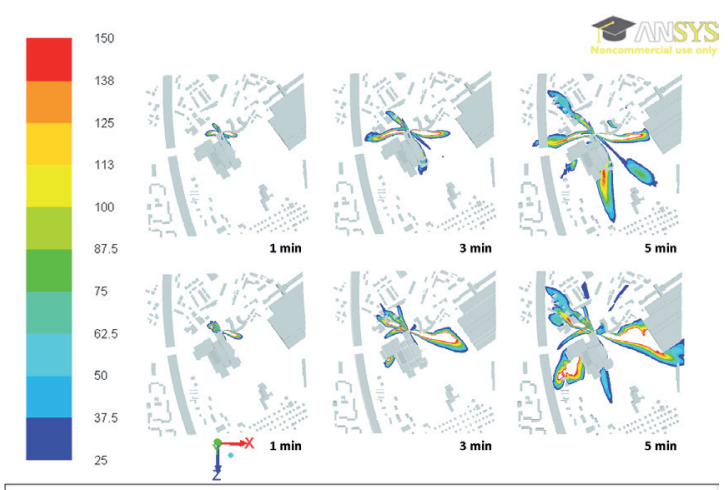

Contours of Concentration $\mathrm{NH}_{3}[\mathrm{ppm}]$

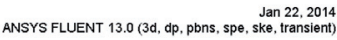

Fig. 3: Filled contours of gas ammonia concentrations in the vicinity of the ice stadium displayed as 2D cross sections of 3D geometry for two seasons of the year and eight wind directions.

\section{Results and Logical Links}

The In the Czech Republic (Central Europe) four seasons are present in the course of the year. Each season is characterized by different meteorological conditions. As a result, the course of accidental releases and dispersion of hazardous substances may differ. Changes of velocities and directions of predominant winds, changes in air temperatures and in escaped pollutant temperatures are particularly important for dispersion and spread of dangerous substances [5]. Within the meaning of the study, in summer the air velocity ranges from 1.1 to $1.6 \mathrm{~m} . \mathrm{s}^{-1}$ whereas in winter it ranges from 1.4 to $2.2 \mathrm{~m} \cdot \mathrm{s}^{-1}$. Evidently, at the location the wind blows faster in winter. The wind rose provided by $\mathrm{CHMl}$ shows that the directions of predominant winds also change. In summer southwest and west winds 
prevail whereas in winter southwest and northern winds do. It may well be said that locations most threatened by an accidental release change with year seasons. The air temperature changes too. In summer the ambient air temperature is around $18.8^{\circ} \mathrm{C}$ whereas in winter it is around $-0.1^{\circ} \mathrm{C}$. These differences cause changes in pollutant density, which can be deduced from the equation of state. From the definition of Froude number $\operatorname{Fr}[6,7]$ it follows that in winter (at lower temperatures) the influence of mass forces on the pollutant plume motion is greater than in summer (at higher temperatures). Therefore, in winter gas ammonia plume keeps closer to the ground and covers larger area.

The influence of surrounding buildings on plume propagation is also important. On the downwind side of large buildings lee vacuum turbulent zones can be observed to form affecting the flow of air and pollutants. These vacuum zones suck in ambient air and pollutants building up areas with higher pollutant concentrations. At the same time they increase the values of turbulent quantities at a given location thereby causing increased pollutant dispersion.

In summary, it may be stated that in winter the accidental release of gas ammonia is more dangerous for people living nearby the ice stadium than in summer. For the purposes of this study, the CFD model had been verified in a low-speed wind tunnel on a gas pollutant motion and dispersion task [5].

\section{Conclusions}

The analysis presented in this article clearly demonstrates the effect of year seasons -or changes of meteorological conditions- on the motion and dispersion of the gaseous pollutant of $\mathrm{NH}_{3}$. The influence of surrounding buildings on the accumulation or dispersion of pollutants, especially where large buildings (factories, hotels, or the ice stadium itself) are located, is indicated. The results of this and similar analyses are widely used in emergency planning, mainly due to a comprehensive mathematical-physical approach to task solving and a wide range of options for evaluation and visualization of results.

\section{Acknowledgments}

This study has been supported by the project of the Ministry of Education, OP Research and Development for Innovations: Innovation for Efficiency and Environment, No. CZ.1.05/2.1.00/01.0036.

\section{References}

[1] Czech Hydrometeorological Institute. Meteorology, from http://www.chmi.cz/, 31.01.2014.

[2] Bojko, M. (2008). Guide for Training of Flow Modeling - FLUENT. VSB - Technical University of Ostrava, Ostrava.

[3] Kozubková, M. (2008). Modeling of Fluid Flow, FLUENT, CFX. VSB - Technical University of Ostrava, Ostrava.

[4] Stull, R.B. (1994). An Introduction to Boundary Layer Meteorology. Kluwer Academic Publishers, Dordrecht.

[5] Zavila, O. (2007). Mathematical Modelling of Turbulent Flow, Heat Transfer and Pollutant Motion in Tunnels (Ph.D. Thesis). VSB - Technical University of Ostrava, Ostrava.

[6] Zavila, O. (2011). CFD simulation of gas pollutant motion and dispersion problem in wind tunnel with respect to Froude number. International Conference on Numerical Analysis and Applied Mathematics-2011, AIP Conference Proceedings 1389, pp. 74-77

[7] Zavila, O. (2012). Physical Modelling of Gas Pollutant Motion in the Atmosphere. Edited by C. Liu, Advances in Modeling of Fluid Dynamics. Rijeka, pp. 51-78. 
Acta Mechanica Slovaca

Journal published by Faculty of Mechanical Engineering - Technical University of Košice

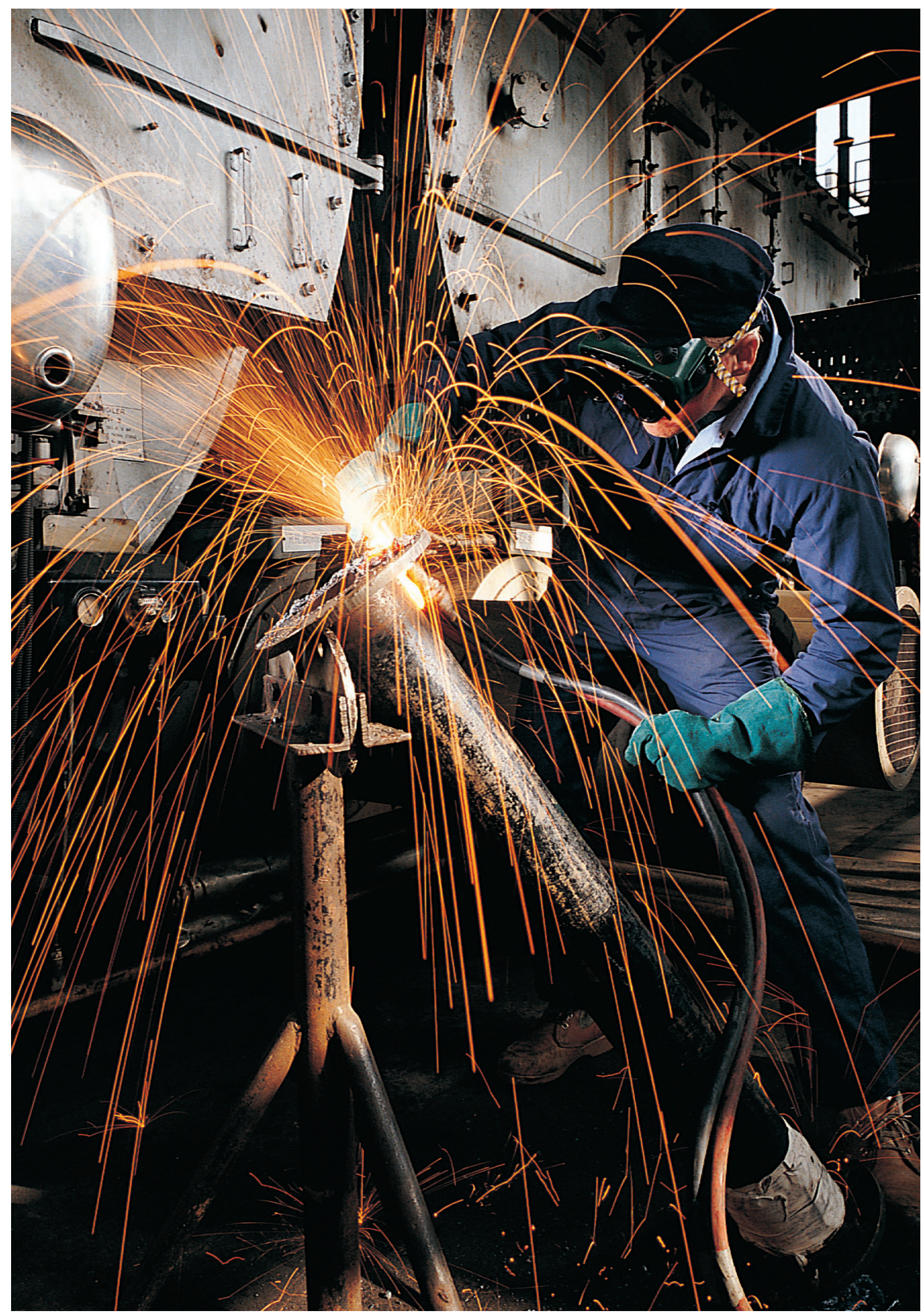

